\title{
S-Shaped Magnetic Macroparticle Filter for Cathodic Arc Deposition
}

S. Anders, A. Anders, M.R. Dickinson, R.A. MacGill, and I.G. Brown Accelerator and Fusion RECEIVED Research Division

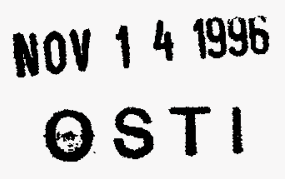

April 1996

Presented at the

17th International Symposium

on Discharges and Electrical

Insulation in Vacuum,

Berkeley, CA,

July 21-26, 1996,

and to be published in

the Proceedings

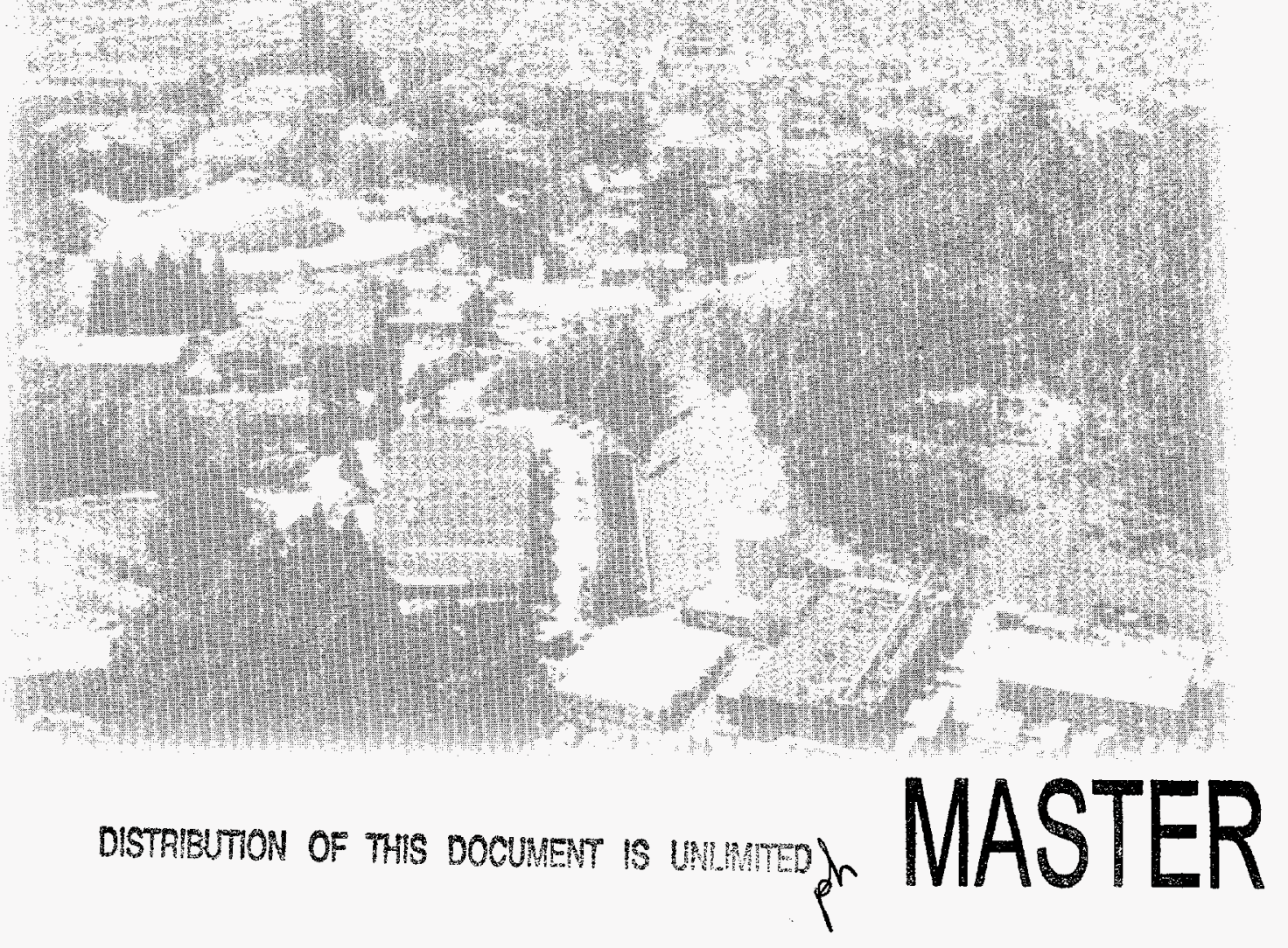




\section{DISCLAIMER}

This document was prepared as an account of work sponsored by the United States Government. While this document is believed to contain correct information, neither the United States Government nor any agency thereof, nor The Regents of the University of California, nor any of their employees, makes any warranty, express or implied, or assumes any legal responsibility for the accuracy, completeness, or usefulness of any information, apparatus, product, or process disclosed, or represents that its use would not infringe privately owned rights. Reference herein to any specific commercial product, process, or service by its trade name, trademark, manufacturer, or otherwise, does not necessarily constitute or imply its endorsement, recommendation, or favoring by the United States Government or any agency thereof, or The Regents of the University of California. The views and opinions of authors expressed herein do not necessarily state or reflect those of the United States Government or any agency thereof, or The Regents of the University of California.

Ernest Orlando Lawrence Berkeley National Laboratory

is an equal opportunity employer. 
Paper to be presented at the

17th International Symposium on Discharges

and Electrical Insulation in Vacuum

Berkeley, July 1996

\title{
S-SHAPED MAGNETIC MACROPARTICLE FILTER FOR CATHODIC ARC DEPOSITION
}

\author{
Simone Anders, André Anders, Michael R. Dickinson, \\ Robert A. MacGill, and Ian G. Brown \\ Lawrence Berkeley National Laboratory \\ University of California \\ Berkeley, CA 94720
}

April 1996

This work was supported by the Electric Power Research Institute under Award number 8042-03, by the U.S. Army Research Office under Award No. ARO118-9.5, and the U.S. Departunent of Energy. Division of Advanced Energy Projects. under contract No. DE-AC03-76SF00098. 
Recycled Paper 


\section{DISCLAIMER}

Portions of this document may be illegible in electronic image products. Images are produced from the best available original document. 


\title{
S-SHAPED MAGNETIC MACROPARTICLE FILTER FOR CATHODIC ARC DEPOSITION
}

\author{
Simone Anders, André Anders, Michael R. Dickinson, \\ Robert A. MacGill, and Ian G. Brown
}

Lawrence Berkeley National Laboratory, University of California, Berkeley, CA 94720

\begin{abstract}
A new magnetic macroparticle filter design consisting of two $90^{\circ}$ filters forming an S-shape is described. The transport properties of this S-filter are investigated using Langmuir and deposition probes. It is shown that the filter efficiency is the product of the efficiencies of two $90^{\circ}$ filters and the deposition rate is still acceptably high to perform thin film deposition. Films of amorphous hard carbon have been deposited using a $90^{\circ}$ filter and the S-filter, and the macroparticle content of the films are compared.
\end{abstract}

\section{INTRODUCTION}

Magnetic filtering is a common technique for removing macroparticles from cathodic arc plasma in order to drastically reduce the macroparticle contamination of the films deposited [1-7]. Various filter designs have been described in the literature; the most common is a $90^{\circ}$ bent filter [1-4], but straight filters [5], $20^{\circ}$ [6], and $45^{\circ}$ filters [7] have also been tested. Filtering is in particular a problem when graphite cathodes are used because the macroparticles are solid and therefore multiply reflected from the filter wall leading to incomplete filtering.

We have designed a new filter consisting of two $90^{\circ}$ filters forming an S-shape. The S-filter has a potential application in the field of hard carbon overcoats of magnetic storage devices where an extremely high quality and extremely low macroparticle contamination is required but film thicknesses are usually small.

\section{EXPERIMENTAL}

\subsection{Filter and source design}

The filter body consisted of a metal bellows bent into an S-shape. The major radius of the bend was $15 \mathrm{~cm}$, the minor radius (inner bellows radius) $4 \mathrm{~cm}$. The guiding solenoid was made from 60 turns of water-cooled copper pipe which was insulated from the bellows. The filter was connected to one of our standard plasma sources [8] which are normally used with $90^{\circ}$ filters. They consist of a $6 \mathrm{~mm}$ diameter cathode surrounded by a cylindrical anode and are triggered by a high voltage spark over an isolating surface around the cathode. The source is equipped with a focusing solenoid of 10 turns around the anode over a length of $3 \mathrm{~cm}$ which can optionally be used to focus the plasma from the source. The source is described in detail elsewhere [8]. Fig. 1 shows a schematic of source, filter, and substrate location.

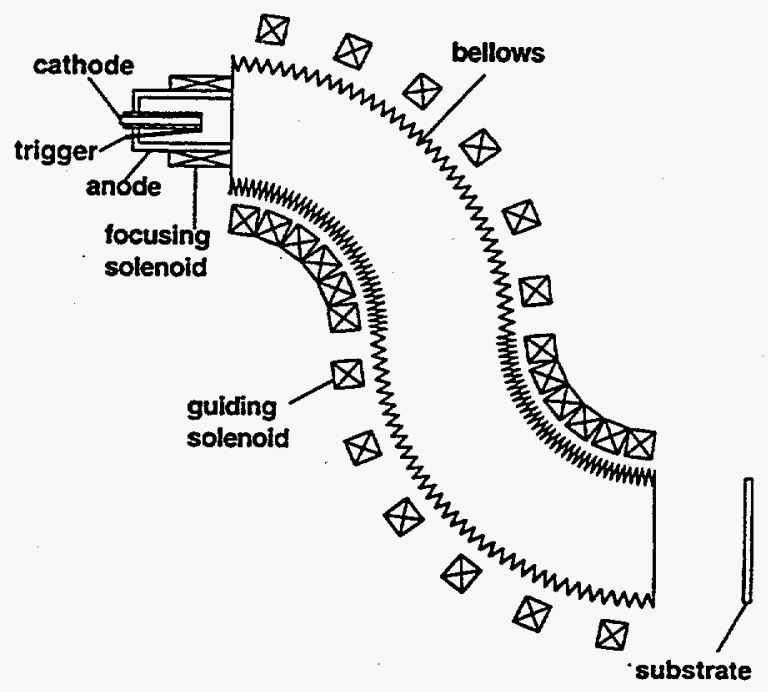

Fig. 1: Schematic of plasma source, S-filter, and substrate location.

As typically for the $90^{\circ}$ filter together with the source, the solenoid of the source and the S-filter were operated in series with the arc current [9]. This mode of filter operation does not allow an independent variation of arc current (plasma density) and magnetic field in the source and filter, but it results in high magnetic field strength, low heat load, and only one power supply is required. On the other hand, it needs a careful design of source and filter so as to have optimum magnetic field configuration at the normal operating arc current.

In an earlier investigation [4] we had found that a magnetic guiding field of about $40 \mathrm{mT}$ represents an optimum for plasma transport. Therefore, we have chosen the number of turns for the guiding field such that at the typical operation current of our source of 250-300 A the magnetic field is between $40-48 \mathrm{mT}$. The plasma source itself was designed for maximum output, and this is achieved at focusing fields greater than about $100 \mathrm{mT}$ [4]. This is not necessarily the optimum field strength for operation with a magnetic filter. As shown in [10], the optimum focusing field is rather in the range of $20-50 \mathrm{mT}$ when the source is used together with a magnetic filter. 


\subsection{Filter operation}

In order to investigate and optimize filter operation, a large, can-shaped Langmuir probe was used which was located at the filter exit and collected all ions emitted from the filter. The probe was biased at $-200 \mathrm{~V}$, and a probe characteristic was taken to verify ion saturation at this voltage.

For all the investigations the anode of the plasma source was at ground potential and the arc power supply was floating. A titanium cathode was used, and the vacuum base pressure was $10^{-6}$ Torr. We studied various configurations. In three cases the focusing solenoid of the plasma source was connected in series with the guiding solenoid of the filter, and the wall of the filter was either connected to ground, was floating, or was connected to the positive potential of the power supply. Figs. 2 shows the total ion current $I_{i o n}$ emitted from the filter normalized to the arc current $I_{\text {arc }}$ as a function of the arc current for all these configurations.

with focusing coil

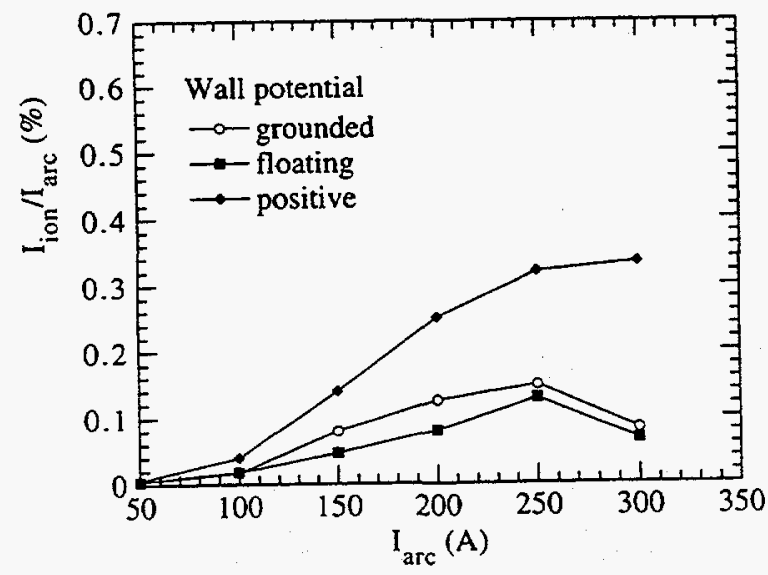

Fig. 2: Iion $/ I_{\text {arc }}$ vs. I arc for plasma source with focusing coil and various filter wall potentials.

In three other cases the focusing solenoid was not connected, the plasma source was slightly inserted into the filter so that the magnetic field of the filter extended up to the cathode surface, and the wall of the filter was either connected to ground, was floating, or was connected to the positive potential of the power supply. Figs. 3 shows the total ion current $I_{i}$ on emitted from the filter normalized to the arc current Iarc as a function of the arc current for all these configurations.

The figures show that the maximum output is $0.6 \%$ of the arc current, and this is $6 \%$ of the total number of ions produced in the arc since the ion current is about $10 \%$ of the arc current [11]. This is the product of the maximum output of two $90^{\circ}$ filters we could achieve so far which is $25 \%$ of the total ion current. [4] This shows that we have obtained the same transport conditions as for our best $90^{\circ}$ filter.

without focusing coil

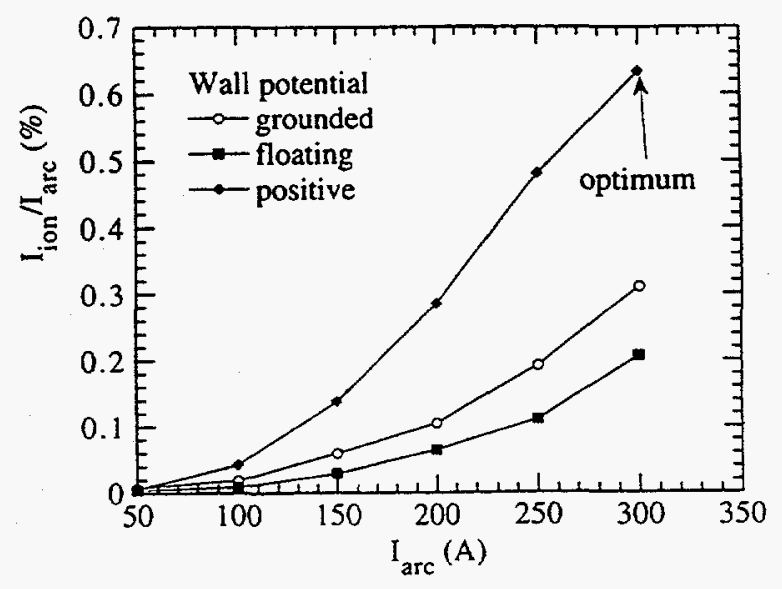

Fig. 3: $I_{\text {ion }} / I_{\text {arc }}$ vs. $I_{\text {arc }}$ for plasma source without focusing coil and various filter wall potentials.

\subsection{Instabilities and filter wall potentials}

At low arc currents the output with focusing coil is slightly higher than without focusing solenoid. This agrees well with the observation that small focusing fields up to $20-50 \mathrm{mT}$ increase transport properties when the source is used with a $90^{\circ}$ filter [4]. At higher current and correspondingly high fields the transport is worse with the focusing solenoid connected and even decreases at very high currents. This is due to instabilities in the transport we have observed in the present investigation which are comparable to instabilities we have found earlier using a $90^{\circ}$ filter [4]. Similar instabilities have been observed also in [12] with a solenoid in the cathodeanode region and were explained as instabilities caused by spot movement toward the cathode edge. Fig. 4 shows the duct output as a function of time during a $5 \mathrm{~ms}$ arc discharge for three different arc currents. Fig. $4 \mathrm{a}$ at 150 A shows a stable output with the usual fluctuation which are caused by the typical noise in vacuum arc plasma production. Fig. $4 \mathrm{~b}$ shows the output at the threshold of the onset of instabilities at $250 \mathrm{~A}$, and Fig. $4 \mathrm{c}$ shows strong instabilities in the output at $300 \mathrm{~A}$. This occurs when the focusing solenoid is connected and the plasma is magnetically shielded from the anode. We did not observe instabilities without focusing solenoid when the plasma can reach the anode. This is in agreement with results found with $90^{\circ}$ filter. 


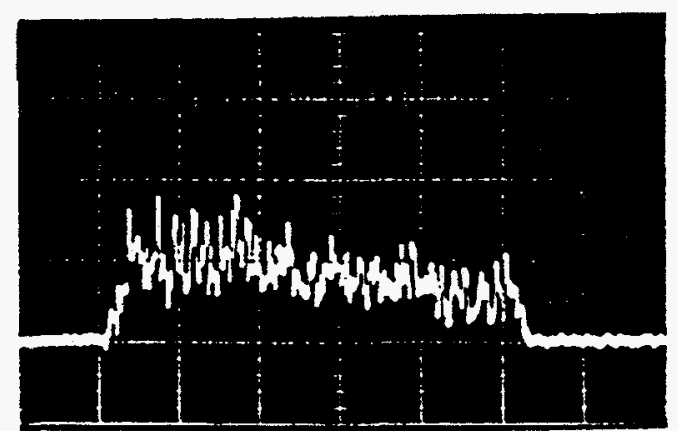

(a)

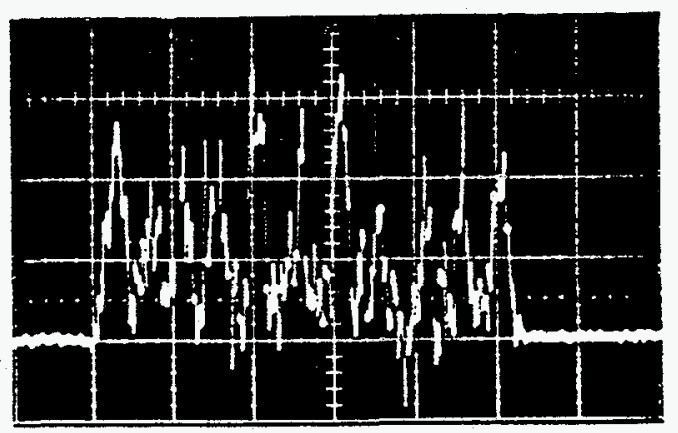

(b)

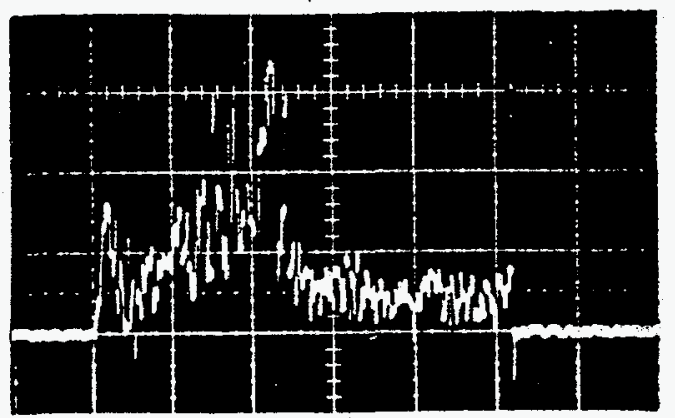

(c)

Fig. 4: Ion saturation current at the Langmuir probe at various arc currents, with focusing solenoid connected. Horizontal - $1 \mathrm{~ms} / \mathrm{div}$, vertical $0.2 \mathrm{~A} / \mathrm{div}$, $4(\mathrm{a})-\mathrm{I}_{\mathrm{arc}}=150 \mathrm{~A}, 4(\mathrm{~b})-250 \mathrm{~A}, 4(\mathrm{c})-300 \mathrm{~A}$.

The difference in the output at various filter wall potential has also been observed before $[13,14]$. The wall potential was measured when the filter was floating and when it was connected to the power supply. Fig. 5 and 6 show the potential of the filter wall $U_{\text {duct }}$ for the various configurations. In accordance with earlier measurements [14] for the $90^{\circ}$ filter a maximum filter transport at the highest positive potential of $15 \mathrm{~V}$ was found, and the lowest transport at the most negative potential of $-20 \mathrm{~V}$.

When we tried to bias the duct wall externally, we observed a breakdown of the applied voltage already at moderate arc currents. This is due to the high plasma density at the filter walls (our filter is much smaller in diameter than most other filters described in the literature). By grounding the anode and connecting the filter wall to the positive potential of the power supply we were able to establish a positive wall potential very close to the optimum potential of +20 $V$ found in [13] which leads to efficient transport without additional power supply.

with focusing coil

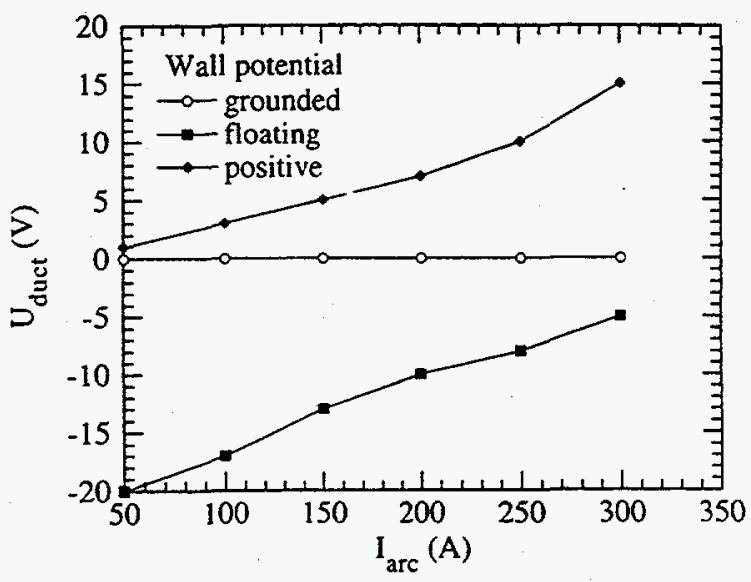

Fig. 5: Wall potential $U_{\text {duct }}$ for plasma source with focusing coil and various configurations of the filter wall connection.

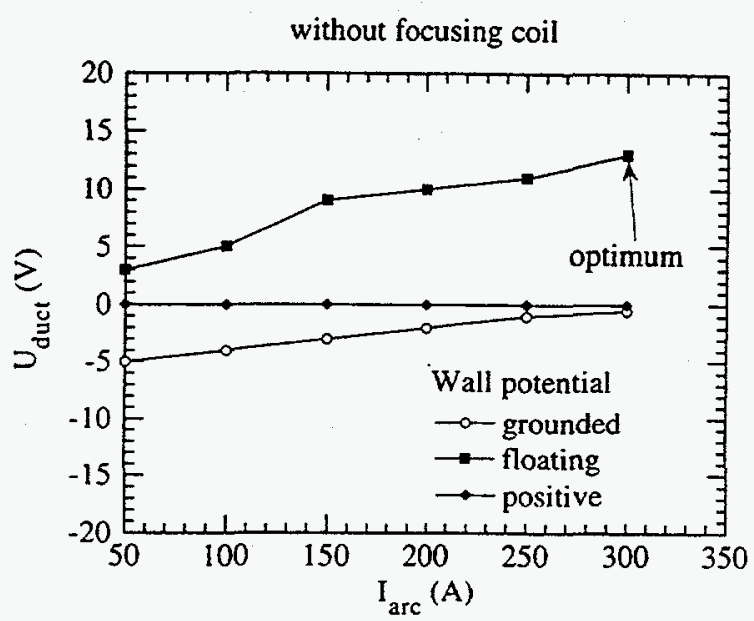

Fig. 6: Wall potential $U_{\text {duct }}$ for plasma source without focusing coil and various configurations of the filter wall connection. 


\subsection{Plasma distribution}

It has been observed by a number of authors that the plasma column in a $90^{\circ}$ filter is not centered at the filter exit although the plasma source is on axis [3, 4]. To investigate the shift of the plasma distribution we deposited a thin, semitransparent titanium films on a transparency with a polar coordinate system which was located at the filter exit and centered to the filter axis. The deposition was performed at optimum deposition conditions as determined in section 2.2. ( $I_{\text {arc }}=300 \mathrm{~A}$, focusing solenoid not connected, filter wall connected to power supply). Fig. 7 shows such a deposition profile.

The plane was horizontal, $90^{\circ}$ was on top, $270^{\circ}$ on bottom, $0^{\circ}$ directed toward the inner side of the second bent (top in Fig. 1), $180^{\circ}$ toward the outer side (bottom in Fig. 1). The figure shows a shift of the plasma to the outer side of the second bend of the filter and a downward shift. The direction of the magnetic field in the filter was opposite to the direction of the plasma stream.

90

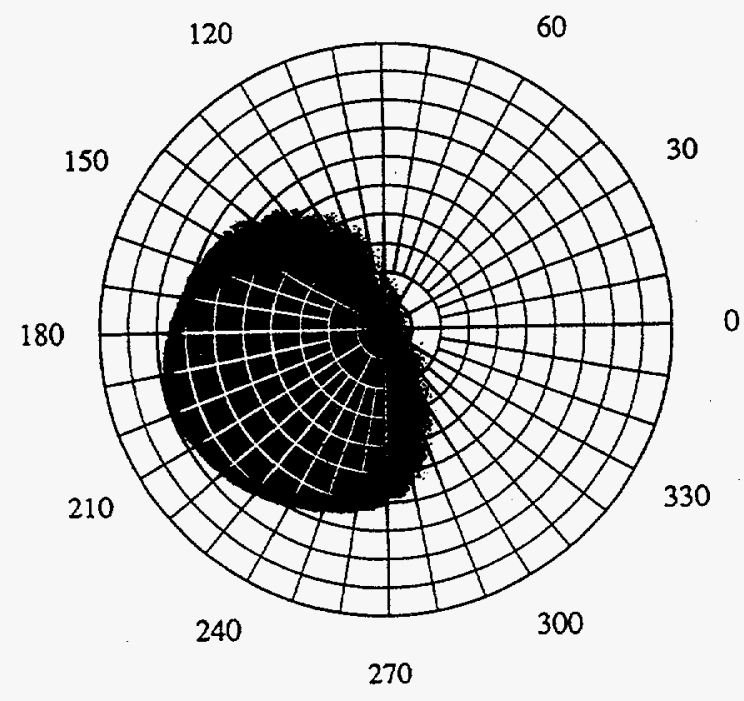

Fig. 7: Plasma distribution at filter exit with source in center of filter entry, titanium plasma, $\mathrm{I}_{\mathrm{arc}}=300 \mathrm{~A}$.

We have moved the position of the plasma source with respect to the duct axis and measured the position of the maximum at the filter exit. Fig. 8 shows the position of the maximum plasma density at filter exit as a function of source position at filter entry.

The staring point of the arrow marks the source position, the tip of the arrow the maximum of the plasma density. Generally, we observe a shift down and to the outer side of the second bent.

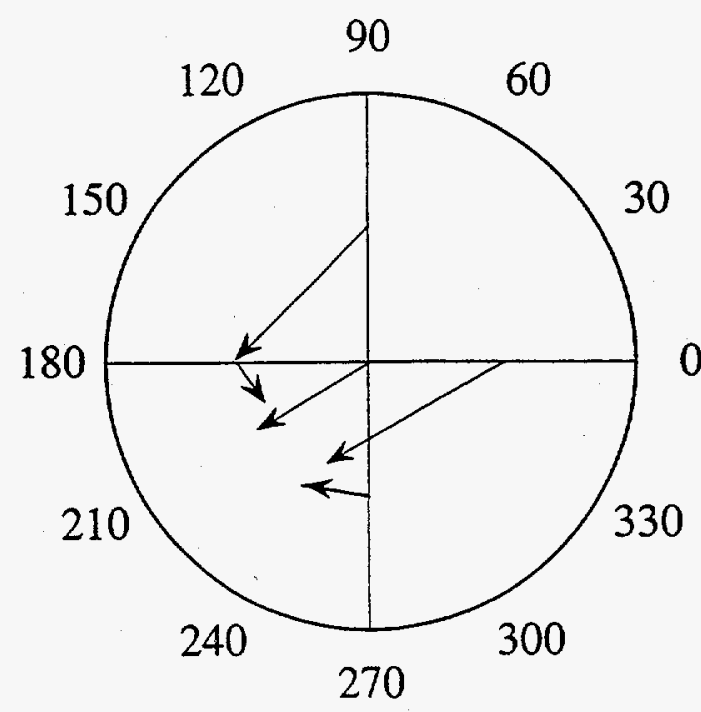

Fig. 8: Shift of the plasma column with respect to the plasma source position. The starting point of the arrows marks the source center, the tip the plasma column center.

\section{DEPOSITION OF AMORPHOUS HARD CARBON FILMS USING THE S-FILTER}

One of the interesting applications of filtered cathodic arc deposition is the formation of amorphous hard carbon films of high quality $[2,5,6,15-17]$. These films exhibit excellent qualities such as high $\mathrm{sp}^{3}$ fraction up to $85 \%$ and high hardness up to 80 $\mathrm{GPa}$. Cathodic arc deposited amorphous hard carbon films are of great interest for a number of applications, e.g. as protective coatings for computer hard disks. So far for this specific application macroparticle have been a tremendous problem. Commercially available filtered vacuum arc deposition facilities produce films which still contain a considerable number of macroparticles.

To compare the macroparticle content of films deposited using a $90^{\circ}$ filter and the S-filter, we have prepared two amorphous hard carbon films. One film was deposited using a $90^{\circ}$ filter described in detail in [9], the other using the S-filter. The films were about $200 \mathrm{~nm}$ thick and formed on Si substrates. The deposition rate for the $90^{\circ}$ filter was about $8 \mathrm{~nm} / \mathrm{min}$, for the S-filter about $2 \mathrm{~nm} / \mathrm{min}$; the sources were operated in a pulsed mode using $5 \mathrm{~ms}$ pulses with a repetition rate of $1.5 \mathrm{~Hz}$ and an arc current of $300 \mathrm{~A}$. The deposition rate can be increased by using a higher duty cycle of plasma production up to dc operation. This would require cooling of the cathode, anode, duct, and maybe also of the sample, but this presents no particular problem. If the $\mathrm{S}$-filter is used with a dc plasma source the deposition rate can be $25 \mathrm{~nm} / \mathrm{min}$. 
Both films were investigated using Scanning Electron Microscopy. On the film deposited using the $90^{\circ}$ filter some carbon macroparticles could be detected. It is difficult to measure a particle density because there are very few in one image when a magnification of 5000 or higher is used, and at lower magnification one is not able to see small macroparticles. As a very rough estimate, we determined the density per deposited area and per deposited film thickness as 100 particles $/ \mathrm{cm}^{2} \mathrm{~nm}$. On the sample deposited using the S-filter we could hardly detect any carbon macroparticles. In a very few cases it was not completely clear whether the particles found on the surface were carbon or dust, but we can say for sure the particle density has been reduced by at least 3 orders of magnitude in comparison to the $90^{\circ}$ filter.

Depositions of amorphous hard carbon films have been performed on computer hard disks also, and they are currently being tested for their applicability. Previously performed deposition of amorphous hard carbon films on magnetic recording heads showed a great improvement in the tribological performance and sufficient quality of the coatings for this application [16].

\section{CONCLUSIONS}

A new magnetic macroparticle filter consisting of two $90^{\circ}$ filters connected to form an S-shape has been developed. At optimum magnetic field configuration and filter wall potential the total output of the filter is $6 \%$ of the input ion current which is the product of the throughputs of two $90^{\circ}$ filters with efficiency of $25 \%$ of the ion current for each $90^{\circ}$ filter. This corresponds to a deposition rate of $2 \mathrm{~nm} / \mathrm{s}$ over an area of about $5 \mathrm{~cm}$ when a dc plasma source is applied.

Amorphous hard carbon films deposited using this filter showed a remarkable reduction in the macroparticle content in comparison to films deposited with a $90^{\circ}$ filter. The new filter is a promising step of development for the application of cathodic arc deposition for magnetic storage devices, in particular for hard carbon overcoats of hard disks, which so far has not been applied due to the relatively high macroparticle contamination of amorphous hard carbon films deposited using $90^{\circ}$ filters.

\section{ACKNOWLEDGMENTS}

This work was supported by the Electric Power Research Institute under Award number 8042-03, by the U.S. Army Research Office under Award No. ARO118-95, and the U.S. Department of Energy, Division of Advanced Energy Projects, under contract No. DE-AC03-76SF00098.

\section{REFERENCES}

[1] I. I. Aksenov, S. I. Vakula, V. G. Padalka, V. E. Strel'nitskii, and V. M. Khoroshikh, Sov. Phys. Tech. Phys. 25, 1164 (1980).

[2] D. R. McKenzie, D. Muller, B. A. Pailthorpe, Z. H. Wang, E. Kravtchinskaia, D. Segal, P. B. Lukins, P. J. Martin, G. Amaratunga, P. H. Gaskell, and A. Saeed, Diamond and Related Mater. 1, 51 (1991).

[3] V. N. Zhitomirsky, L. Kaplan, R. L. Boxman, and S. Goldsmith, Surf. Coatings Technol. 76, 190 (1995).

[4] A. Anders, S. Anders, and I. G. Brown, Plasma Sources Sci. Technol. 4, 1 (1995).

[5] B. F. Coll, P. Sathrum, R. Aharonov, and M. A. Tamor, Thin Solid Films 209, 165 (1992).

[6] R. Lossy, D. L. Pappas, R. A. Roy, J. J. Cuomo, and V. M. Sura, Appl. Phys. Lett. 61, 171 (1992).

[7] S. Falabella and D. M. Sanders, J. Vac. Sci. Technol. A 10, 394 (1992).

[8] A. Anders, S. Anders, I. G. Brown, and I. V. Ivanov, Mat. Res. Soc. Proc. 316, 833 (1994).

[9] S. Anders, A. Anders, and I. G. Brown, J. Appl. Phys. 74, 4239 (1993).

[10] S. Anders, A. Anders, and I. G. Brown, J. Appl. Phys. 75, 4895 (1994).

[11] C. W. Kimblin, IEEE Trans. Plasma Sci. 15, 322 (1982).

[12] V. N. Zhitomirsky, R. L. Boxman, and S. Goldsmith, J. Vac. Sci. Technol. A 13, 2233 (1995).

[13] I. I. Aksenov, V. A. Belous, V. G. Padalka, and V. M. Khoroshikh, Sov. J. Plasma Phys. 4, 425 (1978).

[14] A. Anders, S. Anders, and I. G. Brown, J. Appl. Phys. 75, 4900 (1994).

[15] P. J. Fallon, V. S. Veerasamy, C. A. Davis, J. Robertson, G. A. J. Amaratunga, W. I. Milne, and J. Koskinen, Phys. Rev. B 48, 4777 (1993).

[16] S. Anders, A. Anders, I. G. Brown, B. Wei, K. Komvopoulos, J. W. Ager III, and K. M. Yu, Surf. Coat. Technol. 68/69, 388 (1994).Komvopoulos, J. W. Ager III, and K. M. Yu, Surf. Coat. Technol. 68/69, 388 (1994).

[17] G. M. Pharr, D. L. Callahan, S. D. McAdams, T. Y. Tsui, S. Anders, A. Anders, J. W. Ager III, I. G. Brown, C. S. Bhatia, S. R. P. Silva, and J. Robertson, J. Appl. Phys. 68, 779 (1996). 